\title{
Óleo essencial de Lippia origanoides (Verbenaceae) na higienização de tetos de vacas
}

\section{leiteiras}

\author{
Essential Oil of Lippia origanoides (Verbenaceae) in cleaning of teats dairy cows \\ Aceite esencial de Lippia origanoides (Verbenaceae) en la limpieza de techos de vacas lecheras
}

Anna Christina de Almeida

ORCID: https://orcid.org/0000-0001-9836-4117 Universidade Federal de Minas Gerais, Brasil E-mail: aca2006@ica.ufmg.br

Rodrigo Pereira Morão

ORCID: https://orcid.org/0000-0001-5525-249X Universidade Federal de Minas Gerais, Brasi E-mail: rody.morao@gmail.com

Mário Henrique França Mourthé ORCID: https://orcid.org/0000-0003-3043-358X Universidade Federal de Minas Gerais, Brasi E-mail: kikolider@gmail.com

André Augusto Gomes Faraco ORCID: https://orcid.org/0000-0002-2344-6158 Universidade Federal de Minas Gerais, Brasil

E-mail: andrefaraco@farmacia.ufmg.br

Francine Souza Alves Fonseca ORCID: https://orcid.org/0000-0002-5815-4550 Universidade Federal de Minas Gerais, Brasil

E-mail: francinefonseca@yahoo.com.br Ernane Ronie Martins ORCID: https://orcid.org/0000-0001-6139-7206 Universidade Federal de Minas Gerais, Brasil

E-mail: ernane.ufmg@gmail.com

Livia Mara Vitorino Silva

ORCID: https://orcid.org/0000-0003-3923-7534 Universidade Federal de Minas Gerais, Brasi E-mail: lviavitorino@yahoo.com.br

Cintya Neves de Souza

ORCID: https://orcid.org/0000-0002-3640-8636 Universidade Federal de Minas Gerais, Brasil E-mail: cintyamicro@hotmail.com

Natalia Arantes Marcelo

ORCID: https://orcid.org/0000-0002-0054-488X Universidade Federal de Minas Gerais, Brasi

E-mail: nataliaarantesmarcelo@gmail.com Lucas Gomes Vieira

ORCID: https://orcid.org/0000-0001-8359-5297 Universidade Federal de Minas Gerais, Brasil E-mail: luksgv@hotmail.com

Raphael Rodrigues Porto ORCID: https://orcid.org/0000-0003-1603-9615 Universidade Federal de Uberlândia, Brasil E-mail: raphael.porto@ufu.br

Marcelo Dourado de Lima ORCID: https://orcid.org/0000-0002-0454-7121 Universidade Federal de Minas Gerais, Brasil

E-mail: mlima.2326@gmail.com

Idael Matheus Góes Lopes

ORCID: https://orcid.org/0000-0002-1345-1084

Universidade Federal de Minas Gerais, Brasil

E-mail: idael.matheus@gmail.com

Eliane Macedo Sobrinho Santos

ORCID: https://orcid.org/0000-0002-1576-4957 Instituto Federal do Norte de Minas Gerais, Brasil

E-mail: eliane.santos@ifnmg.edu.br 


\title{
Resumo
}

O presente estudo teve como objetivo avaliar a eficácia de um novo produto elaborado a base de óleo essencial de alecrim pimenta sob a redução da contagem de microrganismos presentes na pele de tetos de vacas leiteiras. Para o teste in vivo, avaliou-se a eficácia do novo produto sob a antissepsia de negativos para mastite clínica (192 tetos), em comparação ao tratamento que continha produtos comerciais (192 tetos), durante um período de 42 dias. Os tetos foram diariamente acompanhados clinicamente, havendo semanalmente avaliação da microbiota presente na pele dos mesmos quanto à redução na contagem de Staphylococcus aureus, Estafilococos coagulase negativo (ECN), Echerichia coli e aeróbios mesófilos. Os dois produtos mantiveram a integridade dos tetos, sendo observado ausência de mastite clínica durante o período experimental. Não observou-se diferença significativa na ocorrência de mastite subclínica e de microrganismos nos tetos dos dois grupos em estudo pelo teste de Fisher em nível de significância de $5 \%$. Ao comparar a redução Log da contagem em UFC.mL $\mathrm{mL}^{-1}$ dos microrganismos para o grupo tratado com produto convencional e com produto experimental para aeróbios mesófilos, E. coli, S. aureus e Estafilococos coagulase negativa, obtidos com o processo de higienização dos tetos foi observada diferença estatística(p>0,05), na contagem de microrganismos, evidenciando que ambos apresentaram efeito semelhante ao controle de microrganismos presentes na pele dos tetos. Sendo assim, o novo produto contendo óleo essencial de alecrim pimenta apresentou eficácia semelhante ao produto convencional clorexidine e iodo para antissepsia dos tetos de vacas leiteiras sem promover reações locais na pele, podendo este vir a ser utilizado como produto alternativo no manejo de ordenha.

Palavras-chave: Antisséptico; Alecrim pimenta; Mastite bovina; Pre-dipping.

\begin{abstract}
The present study aimed with the objective evaluate the effectiveness of a new product made with essential oil of pepper rosemary under the reduction of the count of microorganisms present in the skin of teats of dairy cows. For the in vivo test, the effectiveness of the new product under negative antisepsis for clinical mastitis (192 teats), was evaluated in comparison with the treatment containing commercial products (192 teats), in a period of 42 days. The teats were monitored clinically daily, with a weekly assessment of the microbiota present on their skin as to a reduction in the count of Staphylococcus aureus, coagulase negative staphylococci (SNC), Echerichia coli and mesophilic aerobes. Both products maintained the integrity of the teats, with the absence of clinical mastitis observed during the experimental period. There was no significant difference in the occurrence of subclinical mastitis and microorganisms on the teats of the two groups under study by Fisher's test at a significance level of 5\%. When companing the log reduction of the count in UFC. $\mathrm{mL}^{-1}$ of the microorganisms for the group treated with conventional product and with experimental product for aerobic mesophiles, E. coli, S. aureus and coagulase negative staphylococci, observed with the cleaning process of the teats, a Statistical difference was observed $(p>0,05)$, in the counting of microorganisms, showing that both effect similar to the control of microorganisms present in the skin of the teats. Thus, the new product containing essential oil of pepper rosemary showed similar efficacy to the convencional product chlorhexidine and iodine for antisepsis of dairy cow teats without promoting local reactions on the skin, and can be used as an alternative product in the handling of milking.
\end{abstract}

Keywords: Antiseptic; Pepper rosemary; Bovine mastitis; Pre-immersion.

\section{Resumen}

El presente estúdio tuvo como objetivo evaluar la efectividad de un nuevo producto a base de aceite esencial de pimienta de romero en la reducción del recuento de microorganismos presentes en la piel de los techos de las vacas lecheras. Para la prueba in vivo se evaluó la efectividade del nuevo producto bajo antissepsia negativa para mastitis clínica (192 techos), en comparación con el tratamiento que contenía productos comerciales (192 techos), se evaluó durante un período de 42 días. Los techos fueron monitoreados clínicamente diariamente, con una evaluación semanal de la microbiota presente en su piel para uma reducción en el recuento de Staphylococcus aureus, estafilococcus coagulasa negativos (ECN), Echerichia coli y aerobios mesófilos. Ambos productos mantuvieron la integridad de los techos, con la ausencia de mastitis clínica observada durante el período experimental. No hubo diferencia significativa en la ocurrencia de mastitis subclínica y microorganismos en los techos de los dos grupos en estúdio mediante la prueba de Fisher a um nível de significancia del 5\%. Al comparar la reducción logarítmica del recuento en UFC.mL-1 de los microorganismos para el grupo tratado com producto experimental para mesófilos aerobios, E. coli, S. aureus y estafilococos coagulasa negativos, obtenidos com el processo de limpieza de los techos, se observó diferencia estadística ( $p>0,05)$, en el conteo de microorganismos, demostrando que ambos tuvieron un efecto similiar al control de microorganismos presente en la piel de los techos. Así, el nuevo producto que contiene aceite esencial de pimineta de romero mostró una eficasia similar al producto convencional clorexidine e iodo para antissepsia dos tetos de vacas leiteiras sin promover reacciones locales en la piel, pudiendo ser utilizado como producto alternativo en el manejo del ordeño.

Palabras clave: Antiséptico; Pimienta de romero; Mastitis bovina; Pre-inmersión. 


\section{Introdução}

A implantação de programas de controle para a mastite bovina estão relacionados com a redução dos fatores negativos que essa enfermidade provoca na cadeia produtiva do leite, sendo eles, queda na produção, menor rendimento dos produtos lácteos, diminuição do tempo de prateleira, aumento dos custos com medicamentos, honorários profissionais, descarte de leite durante o período de tratamento e carência, perda de tetos, e descarte de animais (Barbosa, et al., 2020).

Os fatores negativos supracitados são decorrentes de falhas na higienização dos tetos, o que por sua vez acarreta em elevados índices de patógenos precursores de mastite bovina. Os principais patógenos relacionados à mastite bovina são, Staphylococcus aureus e Escherichia coli, pois estes reduzem a qualidade do leite e de seus derivados. Estes microorganismos podem estar presentes no úbere dos animais ou relacionados com os fatores ambientais. A pele dos tetos de vacas pode representar a fonte de populações bacterianas encontradas no leite cru bem como na taxa de mastite e de novas infecções intramamárias, (Baumberger, et al., 2016, Doyle, et al., 2016, Rueg, et al., 2017).

A maioria dos antissépticos utilizados nos tetos antes e após ordenha são compostos por iodo, cloro clorexidine, ácido láctico e amônia quaternária, sendo estes eficazes contra bactérias e leveduras, causadores de mastite (Fitzpatrick, et al., 2021). Porém, o uso em excesso desses produtos pode causar resistência bacteriana aos componentes químicos presentes nos mesmos, em caso de uso rotineiro (Fitzpatrick, et al., 2016), bem como deixar resíduos no leite e seus derivados (Ahvanooei, et al., 2020), podendo comprometer a saúde dos consumidores.

Como alternativa para reduzir esses efeitos negativos, o Ministério da Agricultura, Pecuária e Abastecimento (MAPA), autoriza por meio da Instrução Normativa $\mathrm{N}^{\circ} 64$, de 18 de setembro de 2008, o uso de extratos vegetais para a sanitização de equipamentos e instalações, além de reconhecer o uso desses compostos naturais no tratamento e controle de enfermidades de animais de produção (Brasil, 2008).

Assim, a utilização de produtos como o óleo essencial, que possuem atividade antimicrobiana e antisséptica comprovadas cientificamente frente a bactérias isoladas da glândula mamaria, se faz necessário. A utilização do óleo essencial de alecrim pimenta (Lippia origanoides HBK), que possuí os compostos majoritários timol e carvacrol, é um importante aliado neste quesito, pois sua composição supracitada confere a este o potencial antimicrobiano e antisséptico, promovendo neste caso a redução na taxa de novas infecções intramamárias em uso experimental (Marcelo, et al., 2020).

Diante disso, avaliou-se a eficácia de um novo produto elaborado a base de óleo essencial de alecrim pimenta na contagem de microrganismos presentes em tetos de vacas leiteiras.

\section{Material e Métodos}

O presente estudo foi desenvolvido de forma que as análises fossem de natureza quali-quanti, pois conforme descrito por Perreira et al., (2018), seus resultados apresentam dados numéricos que são complementados com os resultados qualitativos.

\section{Produto testado}

O produto experimental contendo $120 \mu \mathrm{L} / \mathrm{mL}$ de óleo essencial de Lippia origanoides (PEX), foi elaborado no laboratório de farmacotécnica da Faculdade de Farmácia da UFMG, atendendo a todos os critérios recomendados pela legislação brasileira (Brasil, 2012), relacionada aos produtos de uso veterinário, conforme apresentado por Marcelo, et al., (2020).

Para avaliar a qualidade do produto experimental, quanto à permanência dos compostos químicos do óleo utilizado, realizou-se análise do headspace do produto adotando adaptações na metodologia realizada por Aguiar, et al., (2014). Os frascos de headspace $(20 \mathrm{~mL})$, contendo o produto $(1 \mathrm{~mL})$, foram transferidos para o amostrador automático (HS combi-PAL), 
onde foram homogeneizados (500 rpm), incubados $\left(75^{\circ} \mathrm{C}, 5 \mathrm{~min}\right)$, e os voláteis extraídos por headspace estático. O volume de injeção foi definido $(1000 \mu \mathrm{L})$, e a seringa previamente aquecida $\left(75^{\circ} \mathrm{C}\right)$. Para análise de identificação dos voláteis foi utilizado sistema Agilent Technologies (7890A), acoplado ao espectrômetro de massas (MS 5975C), dotado de coluna capilar de sílica fundida DB-5 MS (30 m x 0,25 mm x 0,25 $\mu \mathrm{m}$ ), e hélio (fluxo $1 \mathrm{~mL} \cdot \mathrm{min}^{-1}$ ), como gás de arraste. A programação da temperatura foi de $60{ }^{\circ} \mathrm{C}$ a $240{ }^{\circ} \mathrm{C}$, com um incremento de $3{ }^{\circ} \mathrm{C} \cdot \mathrm{min}^{-1}$. O sistema foi operado no modo scan (monitoramento), com impacto eletrônico a $70 \mathrm{eV}$, em uma faixa de 45 a $550(\mathrm{~m} / \mathrm{z})$.

Os dados gerados foram analisados utilizando o software MSD Chemstation juntamente com a biblioteca NIST, 2009 (National Institute of Standards and Technology). A abundância relativa (\%), dos íons totais referentes aos compostos foi calculada a partir da área de pico do cromatograma (CG), e organizada de acordo com a ordem de eluição. A percentagem de cada componente foi calculada a partir da média normalizada da área do cromatograma. A identificação dos compostos foi realizada por comparação do espectro de massas com o da biblioteca NIST (2.0, 2009), e comparado com informações da literatura (Adams, 2012).

\section{Animais e manejo durante o experimento}

Para o experimento in vivo, a utilização de animais no presente estudo foi conduzida dentro de princípios éticos e de bem estar animal conforme Protocolo n. 230 / 2014 aprovado pela Comissão de Ética no Uso de Animais (CEUA) da Universidade Federal de Minas Gerais.

O experimento foi conduzido nas dependências da Fazenda Experimental do Instituto de Ciências Agrárias da UFMG, na qual foram selecionadas dezesseis vacas da raça Holandês, multíparas, com produção média de 7,34 $\pm 1,52 \mathrm{~kg} / \mathrm{leite} /$ dia, distribuídas aleatoriamente em dois grupos experimentais compostos por oito vacas cada, de acordo com a data do parto, totalizando assim 32 tetos funcionais, com dias em lactação (DEL) de 100 a 200 dias (média de DEL 130 dias). O manejo diário com os animais e o manejo de ordenha (6:00 h e 14:00h) utilizados foram descritos anteriormente por Marcelo, et al., (2020). Para avaliação das possíveis reações locais com uso do novo produto realizaram-se acompanhamento diário do escore da integridade da pele e esfincter dos tetos, segundo Meins al. (2001) com adequações, sendo escore 1 (sem alteração no esfíncter e na pele, normal), escore 2 (leve alteração no esfíncter e na pele e textura macia), escore 3 (alterações visíveis, alteração de textura como áspero e sinais de irritação na pele) a escore 4 (alterações graves no esfíncter, possível reversão e lesões visíveis na pele como rachadura, descamação, vermelhidão).

Após estes procedimentos os produtos foram aplicados por imersão utilizando frasco aplicador apropriado e permaneceram em contato com os tetos por 30 segundos, seguido de secagem com papel toalha após o pré-dipping. Assegurou-se que cada produto fosse utilizado em um mesmo frasco aplicador e que estava abastecido com a quantidade suficiente dos produtos e em condições higiênicas e de uso adequadas durante todo período do estudo.

\section{Protocolos experimentais}

Os grupos experimentais foram identificados como PEX, grupo que recebeu tratamento experimental e CNV, grupo que recebeu tratamento convencional. Nas vacas de cada grupo, os protocolos foram aplicados em dois tetos na posição diagonal estabelecidos aleatoriamente no primeiro dia do experimento e mantido durante todo período experimental, resultando em 192 tetos avaliados ao final de seis semanas, para cada tratamento (Amaral, et al., 2004). Os animais foram identificados com pulseiras nas patas para assegurar o tratamento adequado.

$\mathrm{O}$ tempo de ordenha e o funcionamento do equipamento de ordenha foram acompanhados criteriosamente. No grupo PEX, a higienização dos tetos pré e pós ordenha foram realizadas com o produto experimental. No grupo CNV, a higienização pré ordenha foi realizada com clorexidine $1 \%$ (Hexiderm®, Brasil), e pós ordenha com iodine 2500 p.p.m. (ULTRADIP 
$2500 \AA$, Brasil). Os produtos foram aplicados por imersão utilizando frasco aplicador apropriado e permaneceram em contato com os tetos por 30 segundos, seguido de secagem com papel toalha após o pré-dipping. Assegurou-se que cada produto fosse utilizado em um mesmo frasco aplicador, abastecidos com a quantidade suficiente e em condições higiênicas de uso adequadas durante todo período do estudo. Os mesmos ordenhadores foram mantidos durante todo o período experimental e as vacas eram monitoradas e mantidas em pé com o fornecimento de alimento por 30 min após ordenha, visando o fechamento total do esfíncter do teto e, consequentemente, minimizar a contaminação por patógenos.

No início do período experimental (Dia zero), e a cada sete dias, realizaram-se coletas de amostras para acompanhamento de contaminantes na pele dos tetos, adotando-se a técnica de swabs de arraste realizado na região lateral do terço médio do teto em uma área guia estéril de $\pm 0,5 \mathrm{~cm}^{2}$, em movimentos circulares, antes e após cada tratamento (Braem, et al., 2013). Os swabs foram condicionados em tubos contendo $10 \mathrm{ml}$ de água peptonada $0,1 \%$ estéril e encaminhados para o Centro de Pesquisas em Ciências Agrárias ICA/UFMG para contagem de Aeróbios mesofilos, Staphylococcus aureus, Escherichia coli e estafilococos coagulase negativa (Nickerson, et al.,2012). As análises microbiológicas foram realizadas em duplicada e adotaram-se procedimentos recomendados por Apha (2001), com contagem de UFC por $\mathrm{cm}^{2}$.

A confirmação da espécie para os isolados identificados por técnicas microbiológicas como Staphylococcus aureus foi realizada por PCR através do rastreamento do gene femA e apresentado em publicação prévia de Oliveira et al., (2016). Para isto, os isolados de $S$. aureus criopreservados foram reativados através da semeadura em meio BHI (Laborclin®) e suas colônias isoladas em meio Agar BHI (Laborclin®). Colônias isoladas das placas foram submetidas à extração de DNA com o

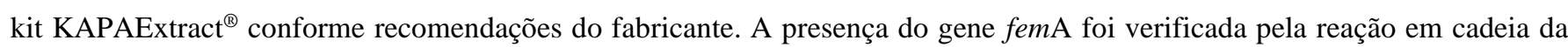
polimerase com os primers fem-A1 5'AAAAAAGCACATAACAAGCG3' ${ }^{\prime}$ e fem-A2 5' GATAAAGAAGAAACCAGCAG3'gerando um amplicon de $132 \mathrm{pb}$ (Dias, 2009), sintetizados pela Integrated DNA Technology, USA. As reações foram realizadas em um mix contendo 1x Tampão da Taq do kit Kappa PCR, $\operatorname{MgCl}_{2}(2,5 \mathrm{mM})$, deoxinucleotídeos $(1 \mu \mathrm{M})$, Taq PolimeraseKappa $(0,5 \mathrm{U}), 1,25 \mu \mathrm{M}$ de cada primer e $1 \mu \mathrm{l}(50 \mathrm{ng} / \mu \mathrm{l})$ de DNA bacteriano em um volume final de reação de $50 \mu$ l. As condições de amplificação foram: um ciclo inicial de desnaturação a $94^{\circ} \mathrm{C}$ durante 5 minutos seguidos de 35 ciclos de desnaturação a $94^{\circ} \mathrm{C}$ por 30 segundos, temperatura de anelamento a $57^{\circ} \mathrm{C}$ por 30 segundos, extensão a $72^{\circ} \mathrm{C}$ por 45 segundos e uma extensão final de 10 minutos.

\section{Análises estatísticas}

A frequência de microrganismos isolados na pele dos tetos após cada tratamento foi avaliada pelo teste não paramétrico Fisher $(\mathrm{p}<0,05)$.

Comparou-se o efeito de cada tratamento na redução da microbiota na superfície da pele dos tetos, realizando-se as contagens de microrganismos obtidas por UFC.mL $L^{-1}$ antes e após cada tratamento. Para padronização dos dados, as contagens foram transformadas na escala logarítmica na base 10, pela fórmula $\log (x+1)$, (Damer, et al., 2015), após, verificou-se a redução logarítmica e comparou-se os tratamentos pelo teste $\mathrm{T}$ pareado $(\mathrm{p}<0,05)$. A redução de Log de cada microrganismo identificado em cada produto foi verificada pelo teste $\mathrm{T}$ pareado $(\mathrm{p}<0,05)$, e a avaliação da capacidade antisséptica foi feita através da análise do teste Tukey $(\mathrm{p}<0,05)$. Também foram avaliados os parâmetros de higienização de tetos de escore de sujidade, integridade dos tetos e teste de CMT verificando possível interferência no uso do produto experimental e produto convencional pelo teste Tukey $(\mathrm{p}<0,05)$.

Realizou-se análise de correlação de Pearson para verificar a associação dos microrganismos isolados dos tetos pelos valores de Log.UFC. $\mathrm{mL}^{-1}$ obtidos nos tratamentos com os parâmetros de escore de sujidade, integridade dos tetos, CMT e CT, utilizando o Software SAS 9.4 (Statistical Analysis System, 2013). As analises estatística foram realizadas utilizandoPROC FREQ do Software SAS 9.4 (Statistical Analysis System, 2013). 


\section{Resultados e Discussão}

A presença do óleo essencial no produto formulado foi comprovada através da análise do headspace estático (Tabela 1). Os principais componentes do óleo essencial de alecrim pimenta se mantiveram no produto elaborado após o processo de formulação sem alteração na composição química.

Tabela 1. Principais compostos voláteis (\%), coletados via headspace estático (HS), e analisados por CG-EM do produto antisséptico e do controle.

\begin{tabular}{ccccc}
\hline $\mathrm{N}^{\circ}$ & Composto & $\mathrm{TR}_{(\min )}$ & $\mathrm{IR}_{\mathrm{Lit}}$ & Íons característicos $(\mathrm{m} / z)$ \\
\hline 1 & $\alpha$-Pineno & 13.5 & 932 & $136\left(\mathrm{M}^{+} 11\right), 121(13), 93(100), 91(50), 79(22)$ \\
2 & Canfeno & 14.5 & 946 & $136\left(\mathrm{M}^{+} 18\right), 121(75), 107(30), 93(100), 91(35)$ \\
3 & $\beta$-Pineno & 16.1 & 974 & $136\left(\mathrm{M}^{+} 10\right), 121(14), 93(100), 91(28), 79(23)$ \\
4 & $\beta$-Mirceno & 17.5 & 988 & $136\left(\mathrm{M}^{+} 4\right), 93(100), 91(22), 69(66), 67(11)$ \\
5 & $\alpha$-Terpineno & 19.0 & 1054 & $136\left(\mathrm{M}^{+} 52\right), 121(91), 105(19), 93(100), 91(53), 77(35)$ \\
6 & m-Cimeno & 20.7 & 1082 & $134\left(\mathrm{M}^{+} 34\right), 120(12), 119(100), 117(16), 91(28)$ \\
7 & Timil metil eter & 32.2 & 1232 & $164\left(\mathrm{M}^{+} 30\right), 149(100), 119(14), 91(19), 77(7)$ \\
8 & Timol & 34.5 & 1286 & $150\left(\mathrm{M}^{+} 30\right), 136(10), 135(100), 115(14), 91(16)$ \\
9 & Cravacrol & 34.9 & 1298 & $150\left(\mathrm{M}^{+} 35\right), 136(10), 135(100), 107(10), 91(17)$ \\
10 & Cariofileno & 39.2 & 1418 & $204\left(\mathrm{M}^{+} 10\right), 189(24), 133(100), 120(45), 119(42)$ \\
\hline
\end{tabular}

TR(min): tempo de retenção. IR(Lit): índice de retenção literatura segundo Van der Dool and Kratz (Adams, 2012). (m/z): íons característicos de cada composto. Fonte: Autores.

O produto experimental utilizado não promoveu nenhuma lesão na pele dos tetos ou qualquer outra reação que indicasse possível toxicidade ou irritabilidade em nenhum dos tratamentos, atendendo as recomendações de que produtos que possam ser utilizados como desinfetantes de tetos devem ser não irritantes e não sensibilizantes para a pele dos tetos, assim como dos tratadores (Brasil, 2009; Nickerson, 2001). A condição da pele do teto é importante e pode ser considerada um aspecto vital da desinfecção do mesmo, sendo esta uma importante aliada nos estudos de eficácia em produtos para higienização (Fitzpatrick, et al., 2021).

A busca por produtos naturais que sejam menos irritantes para a pele dos tetos e dos ordenhadores tem sido estudado em todo o mundo. A irritabilidade na pele dos tetos decorrentes de uso de produtos químicos irritantes é uma reação indesejável, pois além do desconforto, interfere na integridade da pele, promovendo ressecamentos, rachaduras e outras lesões (Nickerson, 2001), predispondo à possíveis focos de infecções que poderão consequentemente afetar o canal do teto e a glândula mamária (Bhutto, et al., 2010; Reyher, et al., 2012; Zoche-Golob, et al., 2015).

No decorrer do trabalho, não foi observada a ocorrência de mastite clínica em nenhum dos tetos em estudo nos dois grupos. Quanto à reação ao teste CMT, observou-se variação ao longo do período de seis semanas, porém estas não foram significativas nos dois grupos estudados. Um fator de exclusão para organização dos grupos experimentais era a presença de mastite clínica e de acordo com os resultados, os produtos utilizados, associados às práticas adequadas de manejo foram eficientes para evitar a ocorrência de infecções intramamárias com apresentação de doença clínica, assim como mantiveram inalteradas estatisticamente os níveis de mastite subclínica no decorrer do tratamento (Tabela 2). Estes resultados são indicativos de que o novo produto atuou de maneira efetiva semelhante ao produto convencional, atendendo ao que se espera da utilização de protocolos corretos na higiene de ordenha. 
Tabela 2. Parâmetros de higienização dos tetos de vacas Holandesa submetidas a dois produtos antissépticos.

\begin{tabular}{lcc}
\hline Dados & Novo produto & Convencional \\
\hline Escorre de sujidade & $1,4323^{\mathrm{A}}$ & $1,4792^{\mathrm{A}}$ \\
Integridade do teto & $1,1250^{\mathrm{A}}$ & $1,1250^{\mathrm{A}}$ \\
California Mastist Test & $1,2240^{\mathrm{A}}$ & $1,2760^{\mathrm{A}}$ \\
\hline
\end{tabular}

Médias acompanhadas por letras maiúsculas não diferem entre si na linha pelo teste Tukey no nível de 5\% de significância. Fonte: Autores.

A higienização correta dos tetos realizada no período experimental contribuiu com a ausência de ocorrência de mastite clínica e subclínica. O mesmo foi observado em estudo realizado por Marcelo, et al. (2020). Pesquisas realizadas em diferentes sistemas de produção (Morton, et al., 2014), também apresentaram resultados semelhantes, bem como na redução de ocorrência de novas infecções intramamárias em condições de campo (Ceballos-Marquez, et al.,2013; Quirk, et al., 2012).

Nas condições deste estudo o escore de sujidade dos tetos manteve-se constante ao longo do experimento (Tabela 2), indicando que estes parâmetros não interferiram na atividade dos produtos, uma vez que a presença de matéria orgânica nos tetos e úbere é fator de risco para ocorrência de infecções intramamárias (Zoche-Golob, et al., 2015; Sandruci, et al., 2014), o que poderia ter interferido com os resultados obtidos neste trabalho. Além da qualidade dos produtos desinfetantes utilizados nos procedimentos de ordenha, a presença excessiva de matéria orgânica nos tetos é um fator que pode interferir na efetividade da escolha de um determinado desinfetante para tetos, havendo neste caso a necessidade de levar em consideração a presença de bactérias no ambiente dos rebanhos leiteiros (Fitzpatrick, et al., 2021).

No presente estudo, identificou-se os microrganismos S. aureus, E. coli e o grupo Estafilococcos coagulase negativa (SCN), na pele dos tetos dos animais avaliados, não sendo observado diferença significativa na ocorrência entre os grupos tratados (Tabela 3). Todos os isolados presuntivamente identificados como S. aureus (6/6), testaram positivos para a presença do gene femA, sendo considerados, portanto, S. aureus e foram apresentados em publicação prévia (Oliveira, et al., 2016), e referem-se as cepas identificadas como CT1E, CT13A, CT11B, CT11C, CT11D e CT11A.

Tabela 3. Microrganismos isolados da pele do teto de vacas leiteiras submetidos a diferentes tratamentos de higienização.

\begin{tabular}{lccc}
\hline & \multicolumn{2}{c}{ Número de tetos positivos } & \\
\cline { 2 - 3 } Microrganismos & Convencional & Novo Produto & Valor de P \\
\hline Estafilococos coagulase negativa. & 21 & 26 & 0,3705 \\
Staphylococcus aureus & 4 & 2 & 0,3186 \\
Escherichia coli & 15 & 8 & 0,1085 \\
\hline
\end{tabular}

Microrganismos isolados dos produtos não diferem entre si na linha pelo teste. Fonte: Autores.

Dentre os microrganismos que apresentaram resistência ao produto e ao óleo de alecrim pimenta aqui testados, o Staphylococcus aureus é considerado de grande importância devido a sua prevalência mundial como patógeno causador de infecções em glândulas mamárias. A identificação de S. aureus, foi observada em 2,08\% (n= 4/ 192), isolados dos tetos tratados com o produto convencional e 1,04\% $(\mathrm{n}=2 / 192)$, com o novo produto, assim torna-se importante avaliar a eficácia do produto teste sobre este agente na pele dos tetos, ainda que pesquisas sobre o papel da pele do teto como uma fonte de $S$. aureus em infecções intramamárias sejam conflitantes e o envolvimento da pele do teto na epidemiologia deste agente é estudada (Mahmmod, et al., 2018; Svennesen, et al., 2018), evidenciando possíveis focos de infecção externas à glândula 
mamária. Resultados de pesquisas indicam que tetos com pele colonizada por $S$. aureus apresentam 4,5 vezes mais riscos de infecções intramamárias do que teto isentos de colonização (Costa, et al., 2014).

A frequência de tetos positivos para estes microrganismos ao longo do período de tratamento também não diferiu estatisticamente entre os grupos analisados pelo teste Fisher em nível de significância de 5\%. Os dados obtidos quanto à microbiota identificada na pele dos tetos (Tabela 3), está de acordo com a descrição na literatura em diferentes sistemas de produção (Baumberger, et al., 2016; Doyle, et al., 2016; Fitzpatrick, et al.; 2016; Rueg, et al., 2017; Fitzpatrick, et al., 2021).

Estafilococos coagulase negativo foi o grupo identificado em maior frequência tanto nos submetidos ao tratamento com novo produto $(13,54 \%)$, quanto ao tratamento com produtos convencionais $(10,94 \%)$, semelhante a outros estudos (Mahmmod, et al., 2018; Svennesen, et al., 2018).

A diversidade microbiana na pele dos tetos, incluindo patógenos ambientais como $E$. coli, foram identificados neste estudo (Tabela. 3), como agentes microbianos com potencial patogênico além da possibilidade de veiculação para leite e, consequentemente, interferir com a qualidade dos produtos lácteos. Estas associações reforçam a necessidade de avaliação de atividades dos produtos utilizados na higienização dos tetos também frente a este grupo de microrganismos. Um fator que pode ter contribuído para a baixa frequência de E. coli, 7,81\% (n=15/ 192), isolados da pele dos tetos tratados com o produto convencional e 4,17\% ( $n=8 / 192)$, com o novo produto observada neste trabalho foram os dados obtidos com escore de sujidades dos tetos (Tabela2), que foram baixos no decorrer do experimento nos dois grupos estudados.

Demais microrganismos que poderiam estar presentes na microbiota da pele dos tetos não foram avaliados, conforme metodologia definida para este trabalho e recomendada por Nickerson, et al., (2004), como indicadores para identificação em testes de eficácia de produtos para uso na higienização dos tetos.

Ao avaliar a carga microbiana em Log da contagem em UFC.mL ${ }^{-1}$ para os diferentes microrganismos isolados (Tabela 4), observa-se que houve redução significativa na contagem destes microrganismos para aeróbios mesófilos ( $\mathrm{p}<0,001), E$. coli $(\mathrm{p}<0,05)$, e Estafilococos coagulase negativa $(\mathrm{p}<0,001)$, presente nos tetos antes e após os tratamentos tanto para os tetos higienizados com novo produto, quanto pelo produto convencional.

A redução de $S$. aureus não foi significativa no grupo submetido ao tratamento com novo produto, e nos tetos componentes do grupo tratado com produto convencional a contagem se manteve constante em 1,12 UFC.mL ${ }^{-1}$.

Tabela 4. Médias em Log.UFC. $\mathrm{mL}^{-1}$ dos swabs da pele dos tetos antes e depois a higienização com o produto convencional e do produto antisséptico contendo óleo essencial de alecrim pimenta.

\begin{tabular}{lllll}
\hline \multicolumn{1}{c}{ Microrganismos } & Produtos & Antes & Depois & Redução de Log \\
\hline \multirow{3}{*}{ Mesófilos } & Convencional & $7,47^{\mathrm{a}}$ & $5,17^{\mathrm{b}}$ & 2,30 \\
\hline \multirow{2}{*}{ Escherichia coli } & Novo produto & $7,51^{\mathrm{a}}$ & $5,74^{\mathrm{b}}$ & 1,77 \\
\hline \multirow{2}{*}{ SCN } & Convencional & $1,66^{\mathrm{a}}$ & $1,38^{\mathrm{b}}$ & 0,28 \\
& Novo produto & $1,39^{\mathrm{a}}$ & $1,21^{\mathrm{b}}$ & 0,18 \\
\hline \multirow{2}{*}{ S. aureus } & Convencional & $2,1^{\mathrm{a}}$ & $1,5^{\mathrm{b}}$ & 0,60 \\
& Novo produto & $2,2^{\mathrm{a}}$ & $1,6^{\mathrm{b}}$ & 0,60 \\
\hline
\end{tabular}

Médias de Log.UFC.mL ${ }^{-1}$ antes e depois acompanhadas por letras minúsculas diferentes diferem entre si $(\mathrm{p}<0,05)$, letras minúsculas iguais não diferem entre si $(\mathrm{p}<0,05)$, na linha para o teste T pareado. Fonte: Autores. 
A variação nos valores de redução de contagem de microrganismos usando a metodologia de avaliação aqui adotada também foi descrita por outros autores com a utilização de produtos comerciais, variando entre produtos e entre os microorganismos identificados (Enger, et al., 2015, Guarin, et al., 2016, Fitzpatrick, et al., 2021). Tal variação pode ser decorrente de contaminação bacteriana natural da superfície da pele do teto relacionado a fatores ambientais, limitações do método de coleta com esfregaços e também tempo de contato do produto (Fitzpatrick, et al., 2021). O tempo de 30 segundos utilizado neste trabalho também foi citado por outros autores.

Em relação a eficácia de diferentes compostos químicos sobre Staphylococcus sp e coliformes, os resultados são variáveis com a classe de agentes químicos. Fitzpatrick, et al., (2021), observaram pequenas diferenças entre níveis de redução de Staphylococcus sp e coliformes no quesito relação entre eficácia e concentração de ingrediente ativo entre 96produtos comerciais agrupados em 9 grupos químicos.

Os resultados aqui obtidos são importantes ao considerar que o efeito foi semelhante ao de produtos convencionais, considerando que esses apresentam alguns inconvenientes na sua utilização, como indução de resistência aos biocidas (Fitzpatrick,et al., 2016 ), e a presença de resíduos no leite, sendo veiculados para bezerros (Van der Reijden, et al., 2018),e para humanos (Ahvanooei, et al., 2021; Ahvanooei, et al., 2020; Coneyworth, et al., 2020; Van der Reijden, et al., 2019), conforme pesquisas que relatam presença de iodo.

Em 2014, National Mastitis Council (NMC) Research Committee publicou uma sumarização de literaturas que avaliaram a eficácia de produtos convencionais utilizados na higienização de tetos, tais como produtos com cloro e iodo, entre outras, em diferentes formulações. Os resultados de eficácia são variáveis entre produtos e microrganismos testados, inclusive semelhança de resultados entre produtos comerciais, conforme obtido neste trabalho. No entanto, nenhum dos 51 trabalhos citados foi avaliado a eficácia de produtos elaborados com óleos essenciais (NMC, 2014).

Pesquisas recentes com "produtos naturais" desenvolvidos para higienização de tetos apresentaram resultados compatíveis com os aqui obtidos ao se comparar o uso de bacteriocinas (Klostermann, et al., 2010), probióticos (Yu, et al., 2017; Alawneh, et al., 2020), do extrato hidroalcoólico de T. minuta (Schiavon, et al., 2011), e de água ozonizada (Cavalcante, et al., 2013), quando comparado com uso de água, produto contendo iodo e produto contendo clorexidine, respectivamente.

Ao avaliar a associação dos microorganismos isolados dos tetos após serem submetidos aos dois tratamentos a avaliação clínica dos tetos (Tabela 5), pode-se observar que apenas S. aureus apresentou correlação positiva e significativa com o escore sujidade, mostrando que falhas no manejo de higienização dos tetos pode ter favorecido a presença deste microrganismo ainda que em baixas contagens. A integridade da pele e do esfíncter não apresentou associação com os microrganismos em estudos, resultados diferentes aos obtidos por outros autores (Bhutto, et al., 2010; Paduch, et al., 2012). Observou-se correlação positiva e significativa entre o isolamento de E. coli em tetos com CMT positivos que compunham o grupo tratado com produto convencional. Para os tetos tratados com o novo produto, observou-se esta mesma associação entre CMT e presença de SCN (Tabela 5). 
Tabela 5. Correlação de Pearson dos parâmetros observados clinicamente e microbiota de tetos submetidos ao tratamento com produto contendo óleo essencial e convencional.

\begin{tabular}{llcccccc}
\hline & & \multicolumn{2}{c}{$\begin{array}{c}\text { Escore de sujidade } \\
\text { dos tetos }\end{array}$} & \multicolumn{2}{c}{$\begin{array}{c}\text { Escore integridade } \\
\text { dos tetos }\end{array}$} & \multicolumn{2}{c}{ Escore de CMT } \\
\hline Microrganismos & Produto & $\mathrm{r}$ & $\mathrm{P}$ & $\mathrm{R}$ & $\mathrm{p}$ & $\mathrm{r}$ & $\mathrm{P}$ \\
& & & & & & & \\
\hline Mesófilos & Convencional & $-0,014$ & 0,851 & $-0,050$ & 0,494 & 0,058 & 0,429 \\
& Experimental & $-0,060$ & 0,408 & 0,018 & 0,807 & 0,008 & 0,917 \\
\hline Escherichia coli & Convencional & $-0,0164$ & 0,8215 & $-0,041$ & 0,5721 & 0,1893 & 0,0086 \\
& Experimental & 0,0128 & 0,8599 & $-0,0499$ & 0,4921 & 0,0414 & 0,5686 \\
\hline S. aureus & Convencional & - & - & - & - & - & - \\
& Experimental & 0,0207 & 0,7757 & $-0,0323$ & 0,6569 & 0,0525 & 0,4699 \\
\hline SCN & Convencional & $-0,0123$ & 0,8656 & 0,0517 & 0,476 & 0,088 & 0,2247 \\
& Experimental & 0,0044 & 0,9512 & $-0,0774$ & 0,2862 & 0,1866 & 0,0095 \\
\hline
\end{tabular}

Valor $\mathrm{r}=$ da correlação; $\mathrm{p}=$ probabilidade obtida no nível de $5 \%$ de significância.

$\mathrm{CMT}=$ California Mastit Test; $\mathrm{SCN}=$ Estafilococcus coagulase negativa. Fonte: Autores.

É importante destacar que E. coli e a maioria dos microrganismos classificados como SCN são considerados oportunistas, mas que também estão associados com a ocorrência de mastite subclínica nos rebanhos além de apresentarem outros fatores de toxicidade associados com a qualidade do leite e produtos derivados (Piessens, et al., 2012; Reyher, et al., 2012; Verdier-Metz, et al., 2012; Morton, et al., 2014). Por isso a prática de higienização dos tetos antes e após a ordenha reduz a ocorrência de mastite, controlando a disseminação dos microrganismos entre os tetos em produção.

\section{Considerações Finais}

O novo produto contendo óleo essencial de alecrim pimenta apresentou eficácia semelhante ao produto convencional clorexidine e iodo para antissepsia dos tetos de vacas leiteiras sem promover reações locais na pele e este poderá vir a ser utilizado como produto alternativo no manejo de ordenha.

Trabalhos futuros envolvendo a aplicação do produto durante o manejo diário da fazenda, com desafios, em condições não controladas, além de avaliações envolvendo a viabilidade econômica ao substituir o produto convencional pelo produto a base de óleo essencial, devem ser conduzidas para sua disponibilização no mercado.

\section{Referências}

Adams, R. B. (2012). Identification of essential oil components by gas chromatogrophy/mass spectrometry. Carol Stream: Allured Publishing Corporation, 804 p.

Aguiar, M. C. S., Silvério, F. O., Pinho, G. P., Lopes, P. S. N. L., Fidêncio, P. H., \& Ventura S. J. (2014). Volatile compounds from fruits of Butia capitata at different stages of maturity and storage. Food Research International, 62, 1095-1099. 10.1016/j.foodres.2014.05.039.

Ahvanooei, M. R., Norouzian, M., \& Hedayati, M. (2020). Iodine Concentration in Iranian Dairy Milk Products and Its Contribution to the Consumer's Iodine Intake. Iranian Journal of Veterinary Medicine, 14(2), 159-165. 10.22059/ijvm.2019.280325.1004984.

Ahvanouei, M. R. R., Norouzian, M. A., Hedayati, M., \& Vahmani, P. (2021). Effect of potassium iodide supplementation and teat-dipping on iodine status in dairy cows and milk iodine levels. Domestic Animal Endocrinology, 74, 106504. 10.1016/j.domaniend.2020.106504.

Alawneh, J. I., James, A. S., Phillips, N., Fraser, B., Jury, K., Soust, M., \& Olchowy, T. (2020). Efficacy of a Lactobacillus-Based Teat Spray on Udder Health in Lactating Dairy Cows. Frontiers in veterinary science, 7, 584436. 10.3389/fvets.2020.584436.

Amaral, L. A., Isa, H., Dias, L. T., Rossi Jr, O. D., \& Filho, A. N. (2004). Avaliação da eficiência da desinfecção de teteiras e dos tetos no processo de ordenha mecânica de vacas. Pesquisa Veterinária Brasileira, 24(4), 173-177, 2004. https://www.scielo.br/pdf/pvb/v24n4/a01v24n4.

Apha, American public health association (2001). Compendium of methods for the microbiological examination of foods. (4th ed.) APHA. 25- 35. https://ajph.aphapublications.org/doi/book/10.2105/MBEF.0222. 
Barbosa, L. N., Almada, A. F. B., Schmitz Junior, J. A., Vechio, M. A. D., Bezerra, K., Espolador, G. F., Santos, M. C. Dos., Moretto, L. De F., Santos, I. C., Martins, L. De A., \&Gonçalves, D. D Bacteriophages' action against mastitis-causing bactéria. Research, Society and Development, 9,10, e1849108541, 2020. 10.33448/rsd-v9i10.8541.

Baumberger C., Guarin J. F., \& Ruegg P. L. (2016). Effect of 2 Different Premilking Teat Sanitation Routines on Reduction of Bacterial Counts on Teat Skin of Cows on Commercial Dairy Farms. Journal of dairy Science, 99(4), 2915-2929. 10.3168/jds.2015-10003.

Bhutto, A. L., Murray, R. D., \& Woldehiwet, Z. (2010). Udder shape and teat-end lesions as potential risk factors for high somatic cell counts and intramammary infections in dairy cows. The Veterinary Journal, 183(3), 63-67. 10.1016/j.tvj1.2008.08.024.

Braem, G., Vliegher, S., Verbist, B., Piessens, B., Van Coillie, E., De Vuyst, L., \& Leroy, F. (2013). Unraveling the microbiota of teat apices of clinically healthy lactating dairy cows, with special emphasis on coagulase-negative staphylococci. Journal of Dairy Science, 96(3), 1499-1510. doi:10.3168/jds.20125493 .

Cavalcante, D. A., Leite Júnior, B. R. C., Tribst, A. A. L., Cristianini, M., \& Coelho, V. R. P. (2013). Uso da água ozonizada na sanitização dos tetos de Bovinos e sua influência na qualidade do leite. Revista do Instituto de Laticínios Candido Tostes, 68(392), 33-39. 10.5935/2238-6416.20130026.

Ceballos-Marquez, A., Hemling, T., Rauch, B. J., Lopez-Benavides, M., \& Schukken, Y. H. (2013). Noninferiority trial on the efficacy of premilking teat disinfectant against naturally occurring new intramammary infections using a novel 2-step diagnostic process. Journal of Dairy Science, 96(12), 8081-8092. doi:10.3168/jds.2013-7108.

Clinical and Laboratory Standards Institute (CLSI). (2012). Methods for Dilution Antimicrobial Susceptibility Tests f or Bacteria That Grow Aerobically; Approved Standard-Ninth Edition. CLSI document M07-A9. Wayne, PA: Clinical and Laboratory Standards Institute; 2012a. http://antimicrobianos.com.ar/ATB/wp-content/uploads/2012/11/03-CLSI-M07-A9-2012.pdf.

Coneyworth, L. J., Coulthard, L. C. H. A., Elizabeth H., Bailey, E. H., Young, D. S., Stubberfield, J., Parsons, L., Saunders, N., Watson, E., Homer, E. M., \& Welham, S. J. M. (2020). Geographical and seasonal variation in iodine content of cow's milk in the UK and consequences for the consumer's supply. Journal of Trace Elements in Medicine and Biology. 59, 126453. 10.1016/j.jtemb.2020.126453.

Costa, L. B., Rajala-Schultz, P. J., Hoet, A., Seo, K. S., Fogt, K., \& Moon, B. S. (2014). Genetic relatedness and virulence factors of bovine Staphylococcus aureus isolated from teat skin and milk. Journal Dairy Science, 97(11), 6907-6916. 10.3168/jds.2014-7972.

Enger, B. D., Fox, L. K., Gay, J. M., Johnson, K. A. (2015). Reduction of teat skin mastitis pathogen loads: Differences between strains, dips, and contact times. Journal of Dairy Science, 98(2), 1354-1361. 10.3168/jds.2014-8622.

Fitzpatrick S. R., Garvey M., Flynn J., Jordan K., \& Gleeson D. (2019). Are some teat disinfectant formulations more effective against specific bacteria isolated on teat skin than others? Acta Veterinaria Scandinavica, 61, 1-5. 10.1186/s13028-019-0455-3.

Fitzpatrick, S. R., Garvey, M., Flynn, J., O’Brien, B., Gleeson, D. (2021). O efeito dos ingredientes desinfetantes nas bactérias da pele do teto associadas à mastite em rebanhos leiteiros irlandeses. Irish Veterinary Journal, 74, 1 (2021). 10.1186/s13620-020-00179-7.

Klostermann, K., Crispie, F., Flynn, J., Meaney, W., Ross, R. P., \& Colin, H. (2009). Efficacy of a teat dip containing the bacteriocin lacticin 3147 to eliminate Gram-positive pathogens associated with bovine mastitis. Journal of Dairy Research, 77(2), 231-238, 2009. 10.1017/S0022029909990239.

Klostermann, K., Crispie, F., Flynn, J., Ross, R. P., Hill, C., \& Meaney, W. (2008). Intramammary infusion of a live culture of Lactococcus lactis for treatment of bovine mastitis: comparison with antibiotic treatment in field trials. Journal of Dairy Research, 75(3), 365-373. 10.1017/S0022029908003373.

Langoni, H. (2013). Qualidade do leite: utopia sem um programa sério de monitoramento da ocorrência de mastite bovina. Revista Pesquisa Veterinária Brasileira, 33(5), 620-626. 10.1590/S0100-736X2013000500012.

Mahmmod, Y. S., Klaas, I. C., Svennesen, L., Pedersen, K., \& Ingmer, H. (2018). Communications of Staphylococcus aureus and non-aureus Staphylococcus species from bovine intramammary infections and teat apex colonization. Journal Dairy Science, 101(8), 7322-7333. 10.3168/jds.2017-14311.

Marcelo, N. A., Andrade, V. A., Souza, C. N., Mourão, R. P., Mourthe, M. H. F., Silva, L. M. V., Xavier, A. R. E. O., Xavier, M. A. S., Faraco, A. A. G., \& Almeida, A. C. (2020). Efficacy of novel antiseptic product containing essential oil of Lippia origanoides to reduce intramammary infections in cows. Veterinary World, 13(11), 2452-2458. 10.14202\%2Fvetworld.2020.2452-2458.

Meins, G. A., Neijenhuis, F., Morgan, W. F., Reinemann, D. J., Hillerton, J. E., Baines, J. R., Ohnstad, I., Rasmussen, M. D., Timms, L., Britt, J. S., Farnsworth, R., Cook, N., \& Hemlimg, T. (2001). Evaluation of bovine teat condition in commercial dairy herds: 1.Non-infectious factors.In: Second International Symposium on Mastitis and Milk Quality Proceedings, BC, Canada, 347-351.

Ministério da Agricultura Pecuária e Abastecimento (2008). Instrução Normativa n64, de 18 de dezembro de 2008. Aprova Regulamento Técnico para os Sistemas Orgânicos de Produção Animal e Vegetal. Diário Oficial da Uniãode 19 de Dezembro de 2008, Seção 1, Página 21, Brasília, DF.

Ministério da Agricultura, Pecuária e Abastecimento (2009). Instrução Normativa MAPA nº 26, de 9 de Julho de 2009. Aprova o Regulamento Técnico para a Fabricação, o Controle de Qualidade, a Comercialização e o Emprego de Produtos Antimicrobianos de Uso Veterinário. Diário Oficial da Uniãode 22 de abril de 2004, Seção 1, Página 211, Brasília, DF.

Morton, J. M., Penry, J. F., Malmo, J., \& Mein, G. A. (2014). Premilking teat disinfection: Is it worthwhile in pasture-grazed dairy herds?. Journal of Dairy Science, 97 (12), 7525-7537. 10.3168/jds.2014-8185.

Nickerson, S. C. (2001). Choosing the best teat dip for mastitis control and milk quality. In NMC-Milk quality conference proceedings, 43. http://www.nmconline.org/articles/teatdip.htm.

Nickerson, S. C., Saxon, A., Fox, L. K., Hemling, T., Hogan, J. S., Morelli, J., Oliver, S. P. Owens, W. E., Pawlak, M., \& Peterson, L. (2004). Recommended protocols for evaluating efficacy of postmilking teat germicides. NMC Annual Meeting Proceedings, 379-399. https://bit.ly/3puxbfN. 
Oliveira, S. P. de, Xavier, A. R. E. de O., Souza, C. N. de, Cunha, G. S. P., Melo Júnior, A. F. de, Xavier, M. A. de S., Sanglard, D. A., \& Almeida, A. C. de. (2016). Identificação genotípica de Staphylococcus aureus multiresistentes a drogas isolados de animais de produção. Caderno De Ciências Agrárias, 8(3), 45-51. https://periodicos.ufmg.br/index.php/ccaufmg/article/view/2942.

Paduch, J. H., Mohr, E., \& Kromekera, V. (2012). The association between teat end hyperkeratosis and teat canal microbial load in lactating dairy cattle. Veterinary Microbiology, 158(3), 353-359. 10.1016/j.vetmic.2012.02.032.

Pereira, A. S., Shitsuka, F. J. Parreira, F. J., \& Shitsuka, R. Metodologia da pesquisa científica. UFSM.

Piessens, V., De Vliegher, S., Verbist, B., Braem, G. Van Nuffel, A., De Vuyst, L., Heyndrickx, M., \& Van Coillie, E. (2012). Characterization of coagulasenegative staphylococcus species from cows' milk and environment based on bap, icaa, and meca genes and phenotypic susceptibility to antimicrobials and teat dips. Journal of Dairy Science, 95(12), 7027-7038. 10.3168/jds.2012-5400.

Piessens, V., Van Coillie, E., Verbist, B., Supré, K., Braem, G., Van Nuffel, A., De Vuyst, Heyndrickx, M., \& De Vliegher, S. (2011). Distribution of coagulase-negative Staphylococcus species from milk and environment of dairy cows differs between herds. Journal of Dairy Science, 94(6), 2933-2944. $10.3168 /$ jds.2010-3956.

Portaria n 101, de 17 de agosto de 1993. (1993). Ministério da Agricultura, Pecuária e Abastecimento. Métodos de Análise Microbiológica para Alimentos. Diário Oficial, 11937-11945

Quirk, T., Fox, L. K., Hancock, D. D., Capper, J., Wenz, J., \& Park, J. (2012). Intramammary infections and teat canal colonization with coagulase-negative staphylococci after postmilking teat disinfection: Species-specific responses. Journal of Dairy Science, 95(4), 1906-1912. 10.3168/jds.2011-4898.

R Development Core Team. (2013). R: A language and environment for statistical computing. R Foundation for Statistical Computing, Vienna, Austria. ISBN 3-900051-07-0. http://www.R-project.org.

Reyher, K. K., Haine, D., Dohoo, I. R., \& Revie, C. W. (2012). Examining the effect of intramammary infections with minor mastitis pathogens on the acquisition of new intramammary infections with major mastitis pathogens - A systematic review and meta-analysis. Journal of Dairy Science, 95(11), 64836502. $10.3168 /$ jds.2012-5594.

SAS Institute Inc. SAS® 9.4 System Options: Reference. Cary, NC: SAS Institute Inc, 2013.

Schiavon, D. B. A., Schuch, L. F. D., Oyarzabal, M. E. B., Prestes, L. S., Zani, J. L., \& Hartwig, C. A. (2011). Aplicación de plantas medicinales para La antisepsia de pezones de vacas posordeño. Revista Cubana de Plantas Medicinales, 16(6), 253-259. http://scielo.sld.cu/scielo.php?script=sci_arttext\&pid=S1028-47962011000300005.

Svennesen, L., Mahmmod, Y. S., Skjølstrup, N. K., Mathiasen, L. R., Katholm, J., Pedersen, K., Klaas, I. C., \& Nielsen, S. S. (2018). Accuracy of qPCR and bacterial culture for the diagnosis of bovine intramammary infections and teat skin colonisation with Streptococcus agalactiae and Staphylococcus aureus using Bayesian analysis. Preventive Veterinary Medicine, 161, 69-74. 10.1016/j.prevetmed.2018.10.013.

Van der Reijden, O. L., Galetti, V., Herter-Aeberli, I., Zimmermann, M. B., Zeder, C., Krzystek, A., Haldimann, M., Barmaz, A., Kreuzer, M., Berard, J., \& Schlegel, P. (2019). Effects of feed iodine concentrations and milk processing on iodine concentrations of cow's milk and dairy products, andpotential impact oniodine intake in Swiss adults. British Journal of Nutrition, 122(2), 172-185. 10.1017/s0007114519001041.

Van der Reijden, O., Galetti, V., Hulmann, M., Krzystek, A., Haldimann, M., Schlegel, P., Manzocchi, E., Berard, J. J., Kreuzer, M., Zimmermann, M. B., \& Herter-Aeberli, I. 2018. The main determinants of iodine in cows' milk in Switzerland are farm type, season and teat dipping. British Journal of Nutrition, 119(5), 559-569. 10.1017/S0007114517003798.

Verdier-Metz, I., Gagne, G., Bornes, S., Monsallier, F., Veisseire, P., Delbès-Paus, C., \& Montel, M.-C. (2011). Cow Teat Skin, a Potential Source of Diverse Microbial Populations for Cheese Production. Applied and Environmental Microbiology, 78(2), 326-333. 10.1128/aem.06229-11.

Yu, J. Yan, R., Xi, X., Huang, W., \& Heping, Z. (2017). A Novel Lactobacilli-Based Teat Disinfectant for Improving Bacterial Communities in the Milks of Cow Teats with Subclinical Mastitis.Frontiers in Microbiology, 8, 1782. 10.3389/fmicb.2017.01782.

Zoche-Golob, V., Haverkamp, H., Paduch, J.-H., Klocke, D., Zinke, C., Hoedemaker, M., Heuwieser, W., \& Krömker, V. (2015). Longitudinal study of the effects of teat condition on the risk of new intramammary infections in dairy cows. Journal of Dairy Science, 98(2), 910-917. 10.3168/jds.2014-8446. 